\title{
Heidegger em confronto com a tradição: \\ o problema da vida fáctica e a destruição fenomenológica contra Natorp e Dilthey
}

\section{Heidegger confronting tradition: the problem of factical life and the phenomenological destruction against Natorp and Dilthey}

Dnda. Juliana Missaggia jumissaggia@gmail.com

PUCRS/CNPq

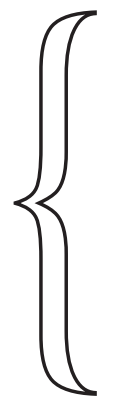

Este artigo analisa as considerações heideggerianas sobre o problema da vida fáctica a partir de seu estudo do pensamento de outros filósofos, especialmente Paul Natorp e Wilhelm Dilthey. Seguindo as análises de Heidegger, esclarecemos a peculiaridade do método de "destruição fenomenológica", um procedimento desenvolvido nos anos 20 como tentativa de apropriar-se da tradição filosófica de maneira original.

PALAVRAS-CHAVE

Heidegger; destruição fenomenológica;

vida fáctica; tradição

This paper examines Heidegger's considerations concerning the problem of factical life as found in his own study of the thought of other philosophers, especially Paul Natorp and Wilhelm Dilthey. In following Heidegger's analyses, we clarify what is distinctive about the method of "phenomenological destruction", a procedure developed during the 1920s as an attempt to appropriate philosophical tradition in a novel way. 
Heidegger em confronto com a tradição: o problema da vida fáctica e a destruição fenomenológica contra Natorp e Dilthey
Dnda. Juliana Missaggia

PUC-RS/CNPq

Com a publicação da Gesamtausgabe, o estudo da chamada "primeira fase" do pensamento heideggeriano ganhou uma série de novos recursos para entender a elaboração do projeto filosófico que resultou em Ser e Tempo. A partir da análise dos cursos ministrados ao longo dos anos 20, podemos perceber como foi necessária uma longa reflexão, o que envolveu tanto a apropriação da filosofia da tradição, como uma nova significação da fenomenologia a partir do confronto com questões até então não resolvidas por ela.

Uma das principais dificuldades que motivaram as reflexões desse período consistia em explicitar um meio para tratar filosoficamente da complexidade inerente à chamada vida fáctica ou concreta, com seu fluxo constante de experiências, sem cair numa objetificação teórica restrita ${ }^{1}$. Se Heidegger já então percebia a limitação que significava confinar filosofia ao escopo de uma teoria anistórica e distanciada da realidade dada, teria que encontrar uma alternativa metodológica eficiente. Ele estava ciente dos problemas teóricos que tal investigação pressupunha, especialmente dentro do contexto de uma filosofia autointitulada fenomenológica.

Diante da tentativa da apreensão da vida fáctica e da aparente impossibilidade da fenomenologia husserliana de tratar da questão, Heidegger concentra seus esforços em enfrentar as dificuldades em torno do tema. O filósofo procura analisar uma possível teoria hermenêutica da formação dos conceitos filosóficos a partir das experiências concretas e percebe que duas seriam as dificuldades iniciais na abordagem dessa questão: a) o problema da validade absoluta e da objetificação do fenômeno da vida, que Heidegger desenvolve como o problema do a priori, e b) o problema do irracional e da vida como experienciável, que seria o problema da experiência "viva" ou concreta.

Encontramos um tratamento detalhado dessas dificuldades no curso de Freiburg de 1920, chamado Phänomenologie der Anschauung und des Ausdrucks ("Fenomenologia da intuição e da expressão"), onde Heidegger analisa criticamente as posições de Natorp e Dilthey. O ponto de partida heideggeriano segue

1 Como o problema da vida concreta ou fáctica liga-se essencialmente ao problema da experiência concreta ou viva é algo que analisaremos ao longo dessa exposição. Às vezes Heidegger utiliza todas essas expressões sem maiores esclarecimentos e como sinônimos. De fato, todos esses conceitos mantém uma relação na medida em que dizem respeito à mesma dificuldade: tratar do problema da vida fáctica é tratar da dificudade de apreensão filosófica das experiências concretas e vivas, tais como são experienciadas nesta vida fáctica. Ainda que Heidegger a princípio não conceitue todos esses termos explicitamente, seus significados e relações ficarão mais claros ao longo da exposição da análise heideggeriana. Além disso, é importante notar que optamos por traduzir o termo faktisch, por "fáctico" e não "fático", ainda que essa palavra soe estranha em português, para seguir o modo como costuma ser traduzida nos estudos de Heidegger em nosso idioma (em inglês é geralmente traduzido como "factical"). Faktizität, por sua vez, traduzimos por "facticidade". 
a noção de facticidade: somente faz sentido discutir questões filosóficas quando estamos de fato filosofando, o que não ocorre se apenas discutirmos a história da filosofia e interpretarmos os textos da tradição; para filosofar realmente, é necessário encontrar nossa própria situação concreta e desenvolver a partir dela as questões que nos são pertinentes.

Segundo Heidegger, parecia claro que a questão mais discutida pelos filósofos nos anos 20 era a dificuldade em torno da expressão filosófica da vida concreta: "a problemática da filosofia contemporânea está centrada em torno da vida como fenômeno original: tanto a vida em geral é colocada como fenômeno original e todas as questões são dirigidas a ela, como cada objeto é entendido como objetificação e manifestação da vida" (HEIDEGGER, 2010, p. 10. GA 59$, p. 15) $)^{2}$. Uma indicação disso são as discussões na escola de Marburg e os trabalhos de diversos filósofos tratando do tema, entre os quais Natorp, Dilthey, Rickert, Spengler e também Husserl.

No entanto, Heidegger reconhece que o próprio sentido do conceito vida é obscuro e aparece com diferenças significativas entre os filósofos que dele se ocupam. Por isso, divide o conceito de vida em dois grupos de significados principais: primeiro, vida como um fenômeno objetificável e, segundo, vida como experienciável. Tais grupos darão origem às duas dificuldades principais na busca por uma teoria de formação dos conceitos filosóficos a partir da vida concreta.

A primeira dificuldade, o problema do a priori, surge a partir do sentido da vida como um processo histórico e em constante transformação, mas que ainda assim pode ser objetificado. Tal significado de vida parte daquilo que entra para a história do espírito como criações da cultura, tanto em seu aspecto teórico, como prático e estético, resultando, desse modo, em três áreas principais do conhecimento: ciência, moralidade e arte. Diante das transformações inerentes ao conhecimento como fruto de um tempo específico, os filósofos passam a preocupar-se em encontrar uma base imutável que fundamente e garanta algum tipo de universalidade para o saber humano.

Devido a tal impasse, busca-se na razão aquilo que consistiria em suas estruturas a priori, pois a despeito das diferenças culturais, éticas, religiosas e estéticas das sociedades, parece que podemos encontrar no aparato cognitivo de todos os homens as semelhanças necessárias para estabelecer algum tipo de universalidade. A matemática e a lógica aparecem em primeiro lugar como um modelo para tal empreendimento, mas a pretensão de fundamentação de um co-

2 Cito, respectivamente, as edições inglesa e alemã do texto, as quais utilizo para a tradução em português. 
nhecimento universal certamente transcende esses campos, e logo fala-se de " $a$ priori ético, estético e mesmo religioso, de validade lógica e ética assim como de validade universal estética e de religião de caráter absoluto; em termos de seu conteúdo é a cada vez um a priori diferente (...), mas é, no entanto, a priori, com validade e lei da razão" (HEIDEGGER, 2010, p. 16. GA 59, p. 22).

A busca é por algo absoluto e justificável por si mesmo, ao contrário da aparente precariedade do fruto do conhecimento humano em sua condição histórica, marcado pela contingência. Essa diferença parece gerar uma cisão no próprio âmago da questão, onde a "unidade relativa e singular de cada formação histórica cultural se opõe à 'generalidade' absoluta e supra-temporal da ideia, do valor e do princípio da razão; a contingência fáctica do histórico em oposição à necessidade supra-histórica do que é irrefutável" (HEIDEGGER, 2010, p. 14. GA 59, p. 20).

Assim, a oposição gerada no interior da questão parece trazer dúvidas quanto à pretensão de universalidade em si mesma: uma vez que o modo como experienciamos o conhecimento é "precário" e ele mesmo parece estar sempre sujeito a constantes revisões, não seria a própria ideia de algo absoluto uma ilusão? Como encontrar uma prova definitiva para o que seria absoluto, uma vez que a apreensão do conhecimento parece dar-se sempre a partir de formas relativas? Supondo que algo desse tipo realmente exista, como conciliar o absoluto e o contingente? De fato, uma série de problemas emerge a partir do confronto entre o absoluto e o relativo, por exemplo, a questão da história (como entender a relação entre o temporal e o supra-temporal) e o problema da cultura e da moralidade (como conciliar os valores relativos das sociedades com um suposto bem universal).

A segunda dificuldade - ligada à ideia do conceito de vida como fenômeno experienciável - surge quando o conhecimento de caráter teórico acaba por ganhar um estatuto de superioridade em relação aos outros tipos de saberes e nos defrontamos com o problema de como analisar filosoficamente o aspecto "irracional" das experiências concretas. De fato, dada a possibilidade de universalidade presente em certos conhecimentos teóricos - como é o caso da matemática - os filósofos tendem a conceber este como sendo o principal, quando não o único, conhecimento por excelência; tal concepção resulta que muitos acabam por desconsiderar outras formas de conhecer. De acordo com Heidegger, esse "perigo da predominância do teórico sobre o desenvolvimento intensificado e vital de possibilidades qualitativamente diferentes de experiências vivas não poderia a longo prazo manter a estrutura da problemática filosófica não afetada" (HEIDEGGER, 2010, p. 17. GA 59, p. 24). Um dos resultados 
Heidegger em confronto com a tradição: o problema da vida fáctica e a destruição fenomenológica contra Natorp e Dilthey
Dnda. Juliana Missaggia

PUC-RS/CNPq

práticos disso é a esterilidade da filosofia acadêmica, que na maioria das vezes não chegaria jamais a produzir algo genuinamente filosófico.

Uma vez que a suposta superioridade do conhecimento teórico é reiteradamente afirmada na investigação filosófica, a própria possibilidade de outros tipos de conhecimento é colocada em questão, quando não simplesmente esquecida - pois para muitos a possibilidade de analisar filosoficamente conhecimentos de caráter não puramente teórico não é sequer concebida. Essa dificuldade está presente em toda a tradição filosófica, o que torna ainda mais complicado perceber as preconcepções presentes na base conceitual que é simplesmente passada adiante sem maiores revisões. É o caso, por exemplo, da própria ideia de "experiência viva", que é concebida geralmente como um fluxo imediato e irracional de dados que somente através de um aparato cognitivo especificamente teórico é capaz de transformar-se em experiências significativas e comunicáveis.

Outro problema ligado a essa segunda dificuldade (da vida como fenômeno experienciável) é a questão da linguagem, que surge a partir da ideia - enfatizada por Bergson em seu Essai sur les données immédiates de la conscience ${ }^{3}$ ("Ensaio sobre os dados imediatos da consciência") - de que todo conhecimento só pode ser comunicado através de uma linguagem que necessariamente está relacionada em sua formação com uma concepção prévia de espaço: a própria lógica da linguagem é uma lógica espacial. Daí surge a dificuldade: além da “teorização em geral, há a inapropriação particular do conceitual como algo separado de um modo espacial da não espacialidade do mental" (HEIDEGGER, 2010, p. 19. GA 59, p. 26); ou seja, há um confronto entre a não espacialidade do conteúdo mental e a conformação espacial dos conceitos comunicáveis.

Aquele que toma as experiências vivas ou concretas como algo que necessariamente possui um elemento irracional e ao mesmo tempo busca por um conhecimento teórico e racional, fica diante do problema da mediação, da dificuldade de estabelecer uma ponte que possa conciliar o fluxo irracional de experiências com sua passagem para uma linguagem de caráter espacial e estruturas próprias: um "conhecimento como formulação da experiência viva enquanto experiência viva significa uma configuração teórica, uma mediação

3 Como diz Bergson (1945, p. 13): "Nós nos expressamos com palavras e pensamos o mais das vezes a partir do espaço. Em outros termos, a linguagem exige que estabeleçamos entre nossas ideias as mesmas distinções claras e precisas, a mesma descontinuidade que existe entre os objetos materiais. Essa comparação é útil na vida prática e necessária para a maior parte das ciências. Mas podemos nos perguntar se as dificuldades insuperáveis que certos problemas filosóficos levantam não vêm do fato de insistirmos em sobrepor ao espaço fenômenos que não ocupam um lugar no espaço, e se, ao não levarmos em conta as grosseiras imagens em torno das quais o combate acontece, não acabaríamos talvez por lhe dar um fim". 
lógica e formalmente guiada (...), uma racionalização do irracional, uma demolição ou imobilização da vida no esquema de conceitos" (HEIDEGGER, 2010, p. 19. GA 59, p. 26). Esse tipo de oposição leva muitos filósofos a buscar em diferentes formas de dialética a solução para tal impasse. Heidegger buscará resolver essa dificuldade a partir da reavaliação dos problemas, de modo a desconstruí-los para encontrar falhas em sua própria formulação. Esse empreendimento acaba por levar a uma apropriação da situação concreta da filosofia e a uma consideração sobre o próprio caráter desta atividade, o que só pode ser realizado através da chamada destruição fenomenológica, a qual será aplicada na análise de Natorp e Dilthey, como exemplos filosóficos da concepção inadequada do conceito de vida.

\section{A destruição fenomenológica como procedimento adequado para enfrentar atradição}

Heidegger reconhece, em primeiro lugar, que o procedimento de análise das questões em torno da formação de conceitos filosóficos, dentro do escopo do problema da vida concreta, esbarra com a questão da apropriação e confronto crítico com a tradição. Não somente deve haver o cuidado de perceber a influência dos filósofos anteriores na maneira como será conduzida a questão, como já deverá ser percebida a dificuldade com os próprios conceitos envolvidos, o que significa algo complexo na medida em que envolve também a questão da linguagem empregada. Conforme apontamos anteriormente, o próprio sentido do termo "vida" parece obscuro, na medida em que varia de significação entre um filósofo e outro. Ainda assim, tal conceito mantém uma unidade do ponto de vista dos problemas que surgem enquanto este apresenta-se como questão filosófica - daí, inclusive, o cuidado de Heidegger em procurar fixar ao menos dois significados gerais para o termo, o que permite o desenvolvimento de duas linhas de problemas a partir de cada um deles.

No entanto, na medida em que Heidegger não pretende realizar uma mera análise linguística, faz-se necessário questionar o próprio sentido de uma destruição fenomenológica $a^{4}$, pois é notório que o conceito mesmo de fenomenologia assume diferentes conotações conforme as diversas correntes que surgiram da apropriação do pensamento de Husserl por outros filósofos. Que seja ne-

4Não caberia aqui tratar de todos os aspectos dessa questão. Para um aprofundamento, ver Jollivet (2004). 
Heidegger em confronto com a tradição: o problema da vida fáctica e a destruição fenomenológica contra Natorp e Dilthey
Dnda. Juliana Missaggia

PUC-RS/CNPq

cessário realizar uma destruição fenomenológica significa que deve haver uma apropriação crítica e transformadora dos conceitos, problemas e procedimentos da filosofia tradicional.

Além disso, na medida em que entra em questão uma investigação do caráter da própria filosofia, pode-se questionar ainda mais radicalmente o procedimento que será usado como ponto de partida: perguntar não somente pelo sentido da fenomenologia como filosofia científica, mas também questionar como a fenomenologia em si mesma é possível. Com isso, de fato, podemos observar que embora Heidegger denomine sua análise como fenomenológica, ele está claramente disposto a questionar em que bases teóricas encontra-se, assumindo que o sentido mesmo de uma filosofia fenomenológica não é tão claro e unificado como Husserl gostaria.

Isso fica ainda mais evidente quando Heidegger - certamente distanciando-se de modo radical da concepção de $\operatorname{Husserl}^{5}$ - afirma que não faz sentido buscar um ponto de partida livre de toda e qualquer preconcepção. De fato, a própria linguagem, seja ela a linguagem natural ou a linguagem filosófica, só possui significado dentro de um contexto linguístico determinado e de acordo com a situação concreta em que o discurso acontece. Segundo Heidegger, "é evidente que toda destruição crítica-fenomenológica é limitada a uma preconcepção - e, portanto, não é fundamentalmente primordial e conclusiva, mas sim pressupõe experiências filosóficas fundamentais" (HEIDEGGER, 2010, p. 25. GA 59, p. 35). Ou seja, a ideia mesma de buscar um procedimento que permita encontrar um fundamento que fundamente a si mesmo - um princípio máximo e de começo radical e definitivo, tal como era a pretensão do projeto cartesiano e do projeto husserliano - é algo que simplesmente não faz sentido, já que ignora o mundo de experiência do qual o homem necessariamente parte.

De fato, o único ponto de partida genuíno para a investigação filosófica seria assumir a situação concreta da vida fáctica, incluindo sua condição histórica e as preconcepções a ela inerentes, pois a "filosofia não consiste em deduzir definições gerais, mas sim é sempre um elemento da experiência da vida fáctica" (HEIDEGGER, 2010, p. 26. GA 59, p. 26). Com isso, é claro, Heidegger não pretende afirmar que a filosofia em nada relaciona-se com a definição de con-

5 A tentativa de Husserl em suas investigações é estar guiado pela ideia de uma "ciência que fundamente com radical autenticidade" e de uma "ciência universal" (HUSSERL, 1986, p. 47. CM., §3). Assim como Descartes, Husserl parte da tentativa de fundamentação radical do conhecimento, sobre bases indubitáveis. Para tanto, é necessário buscar um princípio de evidência que seja em si mesmo auto-fundamentado (o que, no projeto cartesiano, é encontrado através do cogito). Nenhum saber prévio pode ter validade nesse contexto de exigência epistemológica, $o$ que faz com que o conhecimento de todas as ciências seja desconsiderado. 
ceitos e menos ainda significa que devamos restringir o domínio da filosofia à experiência no sentido das experiências empíricas. Ao relacionar filosofia e vida fáctica, pretende-se apontar para o chamado "desvanecimento da significação", que indica a renovação constante dos significados que estão em questão para a investigação filosófica: somente ao assumir e tomar as significações a partir das experiências concretas - remetendo os conteúdos uns aos outros - é que podemos estar de posse do significado mais adequado para uma questão específica, significado esse que levará em conta suas pressuposições e seu contexto histórico.

Em verdade, por trás dessa renovação da fenomenologia efetuada por Heidegger, está o uso do método indicativo-formal, que surge como uma modificação da fenomenologia tradicional em direção a uma apropriação de elementos hermenêuticos. Como o próprio nome diz, indicação formal tem por intenção apontar, indicar uma direção para a qual devemos olhar. E, assim como todo o ato de apontar, há uma incompletude inerente a esse método: a ação de apontar só está completa em seu significado quando alguém olha na direção apontada. Nas indicações formais não há uma determinação conclusiva dos conceitos filosóficos, mas sim uma primeira aproximação. Ao procurar proceder de acordo com o método das indicações formais, dois mal-entendidos bastante comuns em filosofia devem ser evitados: o esquema sujeito-objeto e o preconceito da ausência de perspectiva e ponto de vista.

Trata-se de um modo essencialmente novo na elaboração de conceitos, pois a situação concreta do sujeito que filosofa é levada em conta (como pano de fundo e contexto inevitável da atividade de filosofar), do mesmo modo que se evidencia a modificação que pode haver nos conceitos, já que a noção que serviu de ponto de partida pode alterar-se conforme a análise se desenvolver. A atividade do próprio homem que está filosofando é incluída como um dos elementos fundamentais da filosofia: não podemos ignorar nossa situação concreta e o fato de que, como entes históricos, já partimos de uma perspectiva determinada. Ignorar esse fator e buscar uma "pureza" metodológica que ignora a situação concreta do sujeito filosofante é afirmar o dogmatismo e cair na inevitável dificuldade de fundamentar uma atividade sem a possibilidade de recorrer a elementos externos à própria atividade ou a axiomas primeiros.

É como parte desse novo método fenomenológico elaborado por Heidegger que a destruição fenomenológica tem o seu papel: é necessário reavaliar toda a filosofia da tradição, não somente para aprender com ela, mas também para criticá-la. Além disso, é preciso explicitar que ao procurar aplicar o procedimento de destruição fenomenológica (o que implica partir de suas pressuposições) às 
duas dificuldades da vida concreta, não estamos lidando com questões apenas periféricas à investigação filosófica, que apenas são consideradas na medida em que fazem parte do debate em um momento específico. Tais questões - embora suas formulações sejam marcadas pela terminologia e peculiaridades da filosofia de um tempo específico - estão relacionadas com dificuldades fundamentais e intransponíveis para qualquer filosofar.

A primeira dificuldade, o problema do a priori, diz respeito, como vimos, a oposição entre a validade absoluta do a priori da razão e a contingência do saber histórico. Tal questão não é, como pode parecer à primeira vista, um problema filosófico banal, mas sim diz respeito à própria concepção do que trata a filosofia e de sua possibilidade: falar de um a priori racional implica questionar a estrutura da consciência racional, a ideia e natureza da racionalidade, assim como falar da contingência histórica remete a diversas questões sobre o homem, sua condição e seu modo de estar no mundo, resultando na questão da natureza dos conhecimentos possíveis e de qual é o verdadeiro objeto da filosofia.

A segunda dificuldade - o chamado problema do irracional ou problema da experiência viva - trata da oposição entre a experiência viva (entendida como irracional e não teórica) e a possibilidade de apreender teoricamente (e, portanto, racionalmente) tal esfera. Por trás dessa questão aparece a necessidade teórica do desenvolvimento e da justificação do modo e do método com o qual a filosofia tratará de seus objetos, pois faz-se necessário o questionamento do procedimento teórico que permite apreender adequadamente o objeto da filosofia - seja ela a estrutura $a$ priori da consciência racional, seja o conhecimento histórico e contingente.

\section{O tratamento da primeira dificuldade: o problema do a priori}

O problema do a priori, como vimos, surge devido à aparente oposição entre a condição histórica do homem, marcada pela contingência, e a busca pela validade absoluta fundada no a priori da razão. Uma vez que a questão tem como ponto central a dificuldade em torno do histórico, Heidegger inicia sua análise a partir da investigação dos vários sentidos possíveis para o termo história, já que este é usado com significações diversas dependendo do contexto de seu proferimento. Para tanto, parte da enumeração de sentidos comuns em que empregamos a palavra cotidianamente. 
Seis seriam os sentidos principais em que nos referimos à história: $i$ ) história enquanto a ciência da história, enquanto um ramo do conhecimento humano; ii) história enquanto uma esfera de ser que abrange todos os fatos passados, enquanto uma totalidade fechada e objetiva, da qual podemos extrair características fixas; iii) história enquanto tradição de alguma cultura (o que diferencia-se da história de acontecimentos passados de um povo, na medida em que não diz respeito a fatos ocorridos anteriormente, mas sim a hábitos passados adiante de geração em geração); iv) história como vitae magistra, isto é, concebida enquanto um conhecimento que serve de guia para as decisões de vida, como um instrumento para tomar as decisões presentes a partir das lições passadas; v) história como o conjunto de fatos passados ocorridos com alguma pessoa, ou em algum lugar determinado (a história pessoal de alguém raramente é, por exemplo, objeto de estudo da ciência histórica); vi) em um sentido trivial, também fala-se de história como um acontecimento banal ou um incidente ocorrido com alguém, o qual pode ser relatado como uma história.

Uma vez de posse desses diversos sentidos em que falamos de história, Heidegger observa que em cada um dos casos existe um contexto de significação que só pode ser abarcado completamente levando em consideração não apenas o conteúdo específico de cada sentido, mas principalmente a relação que tais significados mantém entre si e também o modo como são concretamente realizados quando alguém utiliza a palavra em algum caso determinado. Essa análise poderia, possivelmente, também apontar para algum sentido principal ou geral que permitisse encontrar alguma unidade ao termo em questão.

Dito de modo breve, Heidegger procura encontrar as relações fundamentais que as diversas significações estabelecem, para com isso explicitar que a própria inteligibilidade delas depende das relações. Ele mostra que nos sentidos iii, iv e $v$ do termo "história", existe uma relação com o modo pelo o qual tais sentidos são possuídos e experienciados concretamente pelo sujeito, já que somente a partir de tal consideração os sentidos poderiam ser compreendidos de modo adequado; a história como tradição, por exemplo, deve ser analisada a partir da maneira como a tradição é concretamente vivida pelos sujeitos, do contrário a investigação seria completamente vaga, perdendo de vista o próprio objeto em questão. Quanto às outras três significações de história, Heidegger observa que o sentido vi deve ser considerado a partir do fato de que envolve uma tomada de interesse da parte daquele que relata a história, já que ela precisa ser considerada uma história - entre tantos outros fatos ocorridos com alguém, aquele foi considerado digno de nota. Assim, dos sentidos iii até vi, encontramos uma relação que remete diretamente ao Dasein concreto e ao modo como ele experiência o sentido de história. 
No entanto, o sentido $i$ (e também o $i$, pela semelhança quando ao caráter "teórico") chamam a atenção para uma dificuldade: para caracterizá-los, devemos notar que eles estabelecem por si uma complexa relação teórica com outros conhecimentos, necessária para que possam constituir alguma significatividade - a história enquanto ciência, por exemplo, necessita de diversas relações teóricas prévias para ser compreensível enquanto um ramo do conhecimento. Isso não implica, no entanto, que não existam outras relações possíveis, de natureza semelhante àquelas encontradas nos outros sentidos de história.

Nesse caso, porém, como estabelecer a relação mais fundamental? Que relação serviria de fundamento para essas concepções de história? Seria necessário empreender uma investigação teórica sobre relações entre relações? Essa dificuldade dará para Heidegger a ocasião de explicitar os pressupostos que guiam sua análise, o que nos permite observar uma utilização concreta do método das indicações formais, do qual, como vimos, a destruição fenomenológica faz parte.

O objetivo é realizar uma análise que estabeleça a solução para o confronto do conhecimento histórico com a tendência filosófica para o conhecimento de caráter a priori. Em primeiro lugar, Heidegger reconhece que não há uma única maneira pela qual o problema do a priori é formulado e desenvolvido pelos filósofos, mas acredita que podemos encontrar uma base comum que sirva de guia para o tratamento da questão. É notório que em geral não há a pretensão de estabelecer o a priori como algo que simplesmente transcende tudo o que possui caráter histórico, ou como algo que não relaciona-se com o histórico em nenhum sentido. Ao contrário, o a priori costuma ser entendido como a esfera à qual o histórico e o empírico estão subordinados, na medida em que o significado e as normas que guiam essas áreas "contingentes" seriam estabelecidas de modo apriorístico - ganhando, assim, sua fundamentação. Desse modo, o $a$ priori tanto é aquilo que garante a validação para o contingente, como possui em si uma supra-validade: é o absoluto ao qual o contingente está subordinado.

Um exemplo de tratamento mais "aberto" para o problema do a priori, seria a concepção de Rickert ${ }^{6}$. Segundo o filósofo neo-kantiano, é necessário buscar na vida fáctica o material que será investigado aprioristicamente, pois é a historicidade que fornece a multiplicidade de valores que serão avaliados na sua legitimidade e validade, os quais devem também ser classificados de maneira sistemática pelo aparato cognitivo. Através da epistemologia, a filosofia recebe "a autoridade para depositar um valor de conteúdo suprahistórico e, nesse sen-

6Para outras análises heideggerianas sobre Rickert, ver o curso de 1925, Prolegomena zur Geschichte des Zeitbegriffs (GA 20, p. 19-22). 
tido, trabalhar no problema de valores e validade de valores" (HEIDEGGER, 2010, p. 52. GA 59, p. 67). Assim, a filosofia converte-se em uma ciência de valores, onde a validade dos valores é assegurada pelo domínio teórico. Porém, na medida em que tais valores serão atualizados e realizados por um sujeito histórico e concreto, ele mesmo deve ser levado em consideração ${ }^{7}$.

Outro exemplo de análise que procura conciliar o a priori com o histórico aparece na obra do sociólogo Simmel. Segundo Heidegger, Simmel assimila em seu pensamento a metafísica da vida de Bergson e com isso encontra uma solução que combina os dois aspectos aparentemente opostos: a "concreta e unitária dinâmica da vida orgânica (vital) já gera em si mesma 'formas prévias' de configurações ideais" (HEIDEGGER, 2010, p. 53. GA 59, p. 68), as quais formam-se a partir da própria vida, mas ganham autonomia de tal modo que possuem uma lógica própria. Ao gerar por si mesmo uma virada do vital para o ideal, o homem de certo modo liberta-se da vida meramente orgânica e passa a viver em duas esferas concomitantes (a vida orgânica e a vida espiritual). Tal como em Scheler, o homem é ao mesmo tempo um ser vivo e um ser espiritual, no qual só encontramos unidade a partir da consideração desses dois aspectos.

No entanto, todas essas concepções têm algo em comum: guiadas pelo " $a$ priori e recebendo suas normas a partir daí, o acontecimento humano histórico, o processo singular, coloca-se a serviço do a priori. A dinâmica da vida forma-se para além de si mesma, relativamente a algo ideal" (HEIDEGGER, 2010, p. 54. GA 59, p. 68). Trata-se de uma análise essencialmente teórica, na qual o a priori é elaborado em um aspecto epistemológico, como algo que serve de justificativa e explicação para a vida concreta e histórica.

Como Heidegger pretende tratar de outro modo da questão, reconhece ser necessário encontrar um critério para determinar a validade de seus argumentos. Sendo sua análise guiada pelo sentido de realização presente nas significações de história, torna-se fundamental encontrar um critério para definir quando uma realização é genuína ou não. Uma vez que "isso pode ser determinado somente através de uma indicação formal, e do modo necessariamente limitado de realização da indicação formal" (HEIDEGGER, 2010, p. 57. GA 59, p. 74), devemos reconhecer a precariedade da investigação. Tal precariedade manifesta-se, na verdade, como a própria solução da questão: o único ponto

7 De fato, Rickert afirma que "precisamente pelo fato de que isso fornece uma explicação sobre o que está relacionado com um valor geral, a história deve fornecer uma explicação do indivíduo e do distinto. Assim, o indivíduo histórico é significativo para todos por aquilo no qual ele é diferente de todos os outros. Aqueles que acreditam que jamais é o indivíduo mas sim somente o geral que tem uma significação geral falham em perceber que é precisamente o valor mais geral que pode referir ao que é absolutamente individual e único". (RICKERT, 1986, p. 90). 
de partida possível, o único critério pelo qual podemos nos guiar é o mundo-próprio (Selbstwelt) do Dasein, a partir do qual podemos determinar que a realização genuína é aquela que requer uma renovação e atualização constante da realização, de modo a estar o mais completamente envolvida com o próprio fluxo vivo em que as experiências acontecem.

Diante desse critério, fica claro que o sentido $i$ de "história" não pode ser considerado o mais genuíno, na medida em que a relação que é estabelecida não dirige-se ao mundo próprio do Dasein concreto e tampouco a realização necessita ser atualizada numa renovação constante a partir da vida fáctica. Trata-se, ao contrário, de um sentido abstrato e "fechado" de história como uma ciência isolada que não deve relacionar-se com a situação dada a partir de uma atualização constante, já que o ideal de ciência é que ela possua por si mesma - independentemente das contingências da vida fáctica - um aparato conceitual que possa garantir sua legitimidade.

Por sua vez, o sentido iii de "história" (história como tradição), indica uma estrutura de relações entre os "mundos" em que vive o Dasein: ela aponta para o "mundo-circundante (Umwelt) formado, a determinação do mundo-comum (Mitwelt) vivido e possuído, que precisamente preservam a consumação da vida objetiva em sua relação com o mundo-próprio (Selbstwelt)" (HEIDEGGER, 2010, p. 44. GA 59, p. 57). Isso evidencia-se pelo fato de que a história como tradição remete necessariamente ao mundo-comum que é compartilhado com os outros sujeitos da mesma tradição, assim como ao mundo-circundante do qual todos fazem parte. Ao procurar a realização desse sentido de história, não nos remetemos diretamente ao mundo-próprio, mas sim às "instâncias de significação do mundo circundante e do mundo-comum; os mundos-próprios não estão aqui no seu caráter existencial (existenziell), mas apenas têm um papel concomitante ao mundo-circundante" (HEIDEGGER, 2010, p. 63. GA 59, p. 82). O que caracteriza todos esses mundos é a significação na qual são vividos, pois já são sempre significativos para o Dasein de um modo peculiar. Dito isso, podemos perceber que os sentidos $i v$ e vi de história (história como vitae magistra e como incidente, respectivamente), não são de todo genuínos, pois direcionam-se para outros tipos de significações além daquela do mundo-próprio.

Desse modo, também, podemos determinar que o sentido mais genuíno dentre as significações analisadas é aquele de história enquanto passado (enquanto fatos ocorridos). Esse sentido $v$ de história realiza-se em um Dasein concreto, em plena relação com a significatividade do seu mundo-próprio. Seu modo de atualização possui o caráter de sempre dizer respeito aos fatos tal como con- 
cebidos pelo Dasein e por necessitarem de uma reavaliação por parte daquele que experienciou esses fatos. Não há nesse sentido uma necessária remissão a hábitos, ligações de conhecimentos ou saberes compartilhados como no caso de outros sentidos de história. Faz parte da própria característica desse sentido que ele necessite de uma constante atualização de sua realização, pois a história do Dasein concreto não é uma esfera estática que fechou-se em algo como um "passado": uma vez que a vida ocorre no tempo, o próprio passado está em constante transformação e deve ser sempre resignificado.

Por fim, Heidegger aponta no sentido ii de história - história como a totalidade objetiva do passado - a origem mesma do problema do a priori: é ao conceber a história como algo que deve possuir uma totalidade passível de caracterizações gerais e absolutas, apreensíveis teoricamente, que surge o confronto com a suposta contingência da condição fáctica. Se não houver como preconcepção a ideia de um a priori absoluto e eterno, o problema mesmo não se coloca. Do mesmo modo, se a história não for concebida como uma esfera estática da qual devemos extrair as "regras" de funcionamento, tampouco a dificuldade impõe-se. Se o ponto de partida possuir um caráter indicativo-formal e for coerente com a destruição fenomenológica, isto é, tiver como base a vida fáctica do Dasein concreto, então o próprio a priori deverá ser extraído da análise do Dasein histórico e temporal.

Para finalizar, devemos observar que embora a destruição fenomenológica de Heidegger ocorra a partir da recolocação da questão sob um novo ponto de vista (a vida fáctica), não há um maior desenvolvimento da alternativa heideggeriana para substituir o sentido tradicional de a priori, e a análise acaba limitando-se a destruir o modo tradicional de colocar a questão sem, no entanto, propor uma nova problemática e uma nova resposta. Além disso, uma série de termos permanecem obscuros em sua formulação e uso; o filósofo não tem aqui a preocupação de conceituar claramente sua terminologia: o que ele entende, por exemplo, por mundo-próprio (Selbstwelt), mundo-circundante (Umwelt) e mundo-comum ( $M i$ twelt - todos conceitos fundamentais para a questão - é apenas indicado vagamente e compreendido a partir dos pressupostos inerentes à argumentação, mas não há, até aqui, um desenvolvimento detalhado de seus significados. Essa obscuridade na linguagem heideggeriana pode, em parte, ser justificada pelo próprio uso do método da destruição fenomenológica: a intenção é conceber os conceitos de modo que exista a possibilidade de transformá-los ao longo da análise; assim, no lugar de fixar definições, tomamos os conceitos em um significado geral e "testamos" através da investigação se esse significado inicial é adequado. 
Heidegger em confronto com a tradição: o problema da vida fáctica e a destruição fenomenológica contra Natorp e Dilthey
Dnda. Juliana Missaggia PUC-RS/CNPq

\section{O tratamento da segunda dificuldade: o problema da experiência viva e do irracional}

A segunda dificuldade, como vimos, diz respeito ao problema de como a vida enquanto experiência viva é racionalmente acessível para um tratamento filosófico, envolvendo o problema da "irracionalidade" da experiência concreta e a possibilidade de sua apreensão racional e teórica. Em primeiro lugar, Heidegger afirma que também nesse caso, "o modo de proceder é novamente a destruição [fenomenológica], guiada pela mesma preconcepção [do mundo-próprio concreto]" (HEIDEGGER, 2010, p. 70. GA 59, p. 88). E que, ao procurar seguir a tendência filosófica de seus contemporâneos, lidará com questões em torno da relação entre psicologia e filosofia, tanto para definir o modo como devemos entender o "irracional", como para determinar mais claramente os limites entre as duas áreas de conhecimento.

A ambiguidade em torno da questão da experiência viva e do que devemos entender por essa expressão aparentemente vaga é complexa na medida em que envolve sempre uma relação com o sujeito ou consciência que vivencia tal experiência. Assim, tratar dessa dificuldade implica, em primeiro lugar, estabelecer os múltiplos significados em que podemos tomar esses conceitos, assim como a relação que é estabelecida por eles. Nesse sentido, quatro questões fundamentais - motivadas também pelo tratamento filosófico tradicional - devem ser levadas em consideração: a) como as experiências enquanto tais são experienciadas; b) como o caráter de unidade e multiplicidade das experiências vivas é significado nessa experiência; c) como o "eu" relaciona-se com tal caráter de unidade e multiplicidade; d) como o "eu" ele mesmo é experienciado. Dada a enorme dificuldade em torno dessas questões, o ponto de partida heideggeriano será analisá-las a partir da consideração de dois filósofos que trataram do problema: Paul Natorp e Wilhelm Dilthey.

\section{A análise da dificuldade a partir de Natorp}

Heidegger empreende uma exposição do tratamento de Natorp para o problema da experiência viva, a qual descreveremos brevemente. Em primeiro lugar, Heidegger reconhece que procurará guiar-se também aqui pela destruição fenomenológica e que, ao analisar as considerações do filósofo neo-kantiano, terá de avaliar criticamente as afirmações deste, de maneira que seja questionada sua própria concepção de filosofia e seus pressupostos fundamentais. 
Heidegger em confronto com a tradição: o problema da vida fáctica e a destruição fenomenológica contra Natorp e Dilthey
Dnda. Juliana Missaggia

PUC-RS/CNPq

Natorp reconhece que um dos erros metodológicos fundamentais é a objetificação da subjetividade efetuada pela filosofia contemporânea, que costuma opor o objetivo ao subjetivo atribuindo ao primeiro uma superioridade epistemológica. Na experiência sensível, essa diferença fica clara: aquilo que eu posso ver, tocar ou ouvir, são impressões subjetivas que não correspondem a "verdade" das coisas observadas; verdade essa que só pode ser apreendida pelo conhecimento objetivo e científico. Há, desse modo, uma oposição fundamental que pode ser definida a partir de diferentes pontos de vista: objetivo - subjetivo; físico - psíquico; externo - interno; unidade - multiplicidade; forma - matéria.

Para Natorp, há uma relação fundamental entre a objetividade e a subjetividade, pois o objetivo é algo como um "meio" que modela a multiplicidade fornecida pela subjetividade em progressivos graus de objetificação ${ }^{8}$. Há, para cada nível de objetificação, um nível de subjetivação correspondente, os quais devem ser analisados não isoladamente e como algo estático, mas sim em suas relações correlatas e dinâmicas. Todo esse processo é regulado por leis que podem ser de dois tipos fundamentais: as leis do ser e as leis do dever. Tais leis estão ligadas entre si numa unidade anterior à sua separação, garantida pela unidade da própria consciência, por uma "lógica da origem". No entanto, toda e qualquer "representação da subjetividade é sempre subjetivação de algo objetivo" (HEIDEGGER, 2010, p. 81. GA 59, p. 99), já que as leis que regem o processo são apreendidas na representação objetivamente.

Cabe ao filósofo explicitar essa relação mútua através do método da reconstrução $o^{9}$, mostrando que para toda lógica objetiva que determina o processo há um corresponde psíquico subjetivo. Tal método de análise psicológica procura reconstruir a subjetividade, ao distinguir aquilo que é determinável (potencial) daquilo que é determinado (atual). Para cada nível de determinação (atual) há um correspondente potencial; nos dois extremos da consciência encontramos, de um lado, a pura potencialidade e, de outro, a completa determinação (o pen-

8 Como esclarece o próprio Natorp (2007, p. 246): "Se a relação subjetiva e a relação objetiva são opostas uma à outra em um sentido determinado, essa oposição consiste em que a primeira faz abstração da ligação objetiva e a segunda da abstração subjetiva. Mas, assim, as duas considerações são abstrações uma da outra. O conteúdo último, absoluto, conterá o fundamento dessas duas considerações (...). Contudo, podemos dizer que esta determinação objetiva conduz também à procura da subjetividade, como um complemento que ela necessariamente exige (...).

9 Segundo Natorp (2007, p. 222): “o método da pesquisa psicológica que é fundamentalmente diferente desse da ciência da natureza, assim como de todo conhecimento objetivo em geral, é a 'reconstrução' do imediato da consciência a partir do que foi formado por ela - a partir das objetivações (...). Ele consiste, conforme a isso que foi dito, em: (...) introduzirmos isso que estava separado pela abstração em suas ligações originais, restaurarmos no movimento os conceitos estáticos, e assim nos aproximarmos novamente do fluxo vital da consciência e, em meio a tudo isso, reconduzirmos o que estava objetivado às diferentes etapas da doação subjetiva". 
Heidegger em confronto com a tradição: o problema da vida fáctica e a destruição fenomenológica contra Natorp e Dilthey
Dnda. Juliana Missaggia

PUC-RS/CNPq

samento do pensamento $)^{10}$. A pura potencialidade é "o caos a partir do qual emerge a totalidade do mundo formado na consciência" (HEIDEGGER, 2010, p. 84. GA 59, p. 105), isto é, o fluxo contínuo e desordenado da experiência viva. Assim, para o que chamamos, por exemplo, de "sensação" ou "eu" há uma esfera correlata enquanto um momento individual do "caos" da experiência viva; o $e u$ da experiência viva é uma potência do $e u$ atual da representação (do eu determinado). Seguindo essa lógica, na unidade máxima de determinação, o eu já não seria mais um eu individual, mas sim a consciência universal, o sujeito ideal "em geral"."

A partir dessa exposição - ainda que bastante geral ${ }^{12}$ - do procedimento de Natorp, podemos analisar as quatro questões colocadas acima com relação ao ponto de vista do filósofo neo-kantiano. A questão de como as experiências enquanto tais são possuídas, remete diretamente ao método da reconstrução, pois este já revela em si os pressupostos epistemológicos que determinam a análise. Uma vez que o método já determina previamente que as experiências vivas estão na esfera do subjetivo, às quais - de acordo com o próprio método - possuem um correspondente objetivo, haveria a dificuldade de encontrar um meio para avaliar o método ele mesmo, de modo a encontrar os pressupostos que guiam esse resultado (do contrário, a resposta para a questão acabaria por resumir-se a explicitar novamente o método).

A segunda questão, de como a unidade e multiplicidade das experiências vivas são significadas na sua concretização, deve, de acordo com Natorp, evitar o perigo comum da filosofia transcendental de tomar a subjetividade como algo fixo e não compreender sua correlatividade ao objetivo. Nesse caso, é necessário questionar a relação entre a objetividade e a subjetividade do modo mais radical possível, a partir de uma lógica geral. O primeiro a se observar é o papel fundamental dos conceitos de potência e atualização nessa análise: a "pura potência ou o imediato que não é ainda articulado em nenhuma divisão e diferenciação, o qual está antes da articulação, isto é, antes da atualização" (HEI-

10 Ver Kisiel (1995, p. 131).

11 Nas palavras de Natorp (2007, p. 256): “Com o conceito de 'vida' nós projetamos, no entanto, todas as relações que a ciência laboriosamente destaca de uma forma abstrata, como ativas e conscientes atualmente e originariamente. E, da mesma maneira, nós pensamos por esse ideal uma 'consciência' universal, absolutamente concreta. (...) Essa 'ficção' [como a concebem alguns] encontra seu lugar e sua justificação não na psicologia como tal, mas sim na sua metodologia".

12 Ressaltamos que a interpretação aqui apresentada baseia-se, sobretudo, na análise heideggeriana sobre Natorp, já pressupondo alguns pontos de sua filosofia. Não caberia aqui desenvolvê-la mais extensamente. Para uma análise mais detalhada, remetemos ao trabalho de Natorp que citamos anteriormente: Psychologie générale selon la méthode critique. 
DEGGER, 2010, p. 91. GA 59, p. 116), possui também como correlato aquilo que é o puramente atual, totalmente determinado. Mas entre esses dois extremo opostos $^{13}$ - o puramente potencial e o puramente atual - existe aquilo que pode ser experienciado e que contém divisões de níveis e direções de consciência, que devem ser analisados em sua concretização. Somente uma lógica que perpasse tanto o subjetivo como o objetivo, tanto o potencial como o atual - e que, de fato, explique suas relações e regras de interação - poderá determinar a questão.

Assim, surgem duas dificuldades: primeiro, explicitar com máxima generalidade a lógica que guia o processo; depois, explicar como essa lógica realiza-se com maior concretude na consciência individual e singular. A segunda dificuldade serve de guia para a primeira, uma vez que no individual - devido a sua singularidade e particularidade já definidas - encontramos a máxima determinação lógica. $\mathrm{Na}$ análise concreta da consciência individual, porém, percebemos que ainda que ela necessite de uma determinação, é difícil caracterizar a natureza desta: não podemos fixá-la como um gênero estático, pois sua própria existência acontece em uma sequência dinâmica; caracterizá-la a partir de leis gerais de organização (que de fato existem) perderia de vista sua existência concreta, que ocorre num fluxo contínuo (temporal).

Diante de tal dificuldade, Natorp apela para uma caraterística fundamental da consciência consciente: ela deve conhecer a si mesma enquanto uma consciência individual, ela deve ser autoconsciente. Disso, ele parte para o argumento de que somente a consciência que conhecer a si mesma na totalidade máxima de suas determinações pode encontrar a lógica de funcionamento que a guia: afinal, se o que a caracteriza é sua autoconsciência, quanto mais autoconsciente ela for, mais poderá entender a própria lógica de sua determinação. Assim, segundo Natorp, segue-se que a consciência deve buscar o maximamente determinado e absolutamente universal, que corresponde à ideia de Deus, da autoconsciência absoluta (a consciência mais autoconsciente possível). Nesse sentido, não há um primado da subjetividade ou da objetividade, pois ambas têm uma unidade primordial na consciência absoluta e universal. Para Heidegger, esse último passo dado por Natorp faz com que sua filosofia constitua um idealismo absoluto.

A terceira questão, de como o eu relaciona-se com o caráter de unidade e multiplicidade das experiências vivas também remete ao problema do método,

13 Nas palavras de Natorp (2007, p. 267, grifo nosso): “Essa é a 'unidade' do diverso, pelo qual nós exprimimos, a partir de agora, isso que caracteriza o pensamento e, portanto, a atualidade própria da consciência (pensada ainda unicamente do ponto de vista teórico) e, em oposição, nos estágios da potência, ambos (o um e o diverso) que podem e devem ser necessariamente pensados como separados". 
enquanto o eu é um dos momentos do processo metodológico. Há, certamente, uma remissão à questão da consciência, na medida em que o $e u$ diz respeito ao conteúdo desta, de uma unidade que permeia a multiplicidade dos dados conscientes. Toda e qualquer noção de $e u$, assim como a unidade e multiplicidade das experiências, só podem ser dados a partir de uma consciência, por isso qualquer questão em torno do eu remete em verdade ao problema de como o eu pode ser um objeto para a consciência.

Isso também já indica o caminho para a quarta questão: saber como o eu ele mesmo pode ser experienciado remete à sua relação com a consciência. $\mathrm{O}$ $e u$ não pode ser um objeto para a consciência de modo a manter uma relação lógica com outros conteúdos a partir de um pressuposto de igualdade - no qual poderíamos dizer que algo é subordinado ou subordina logicamente o eu -, pois se trata de uma relação essencialmente diversa. De fato, o eu não é um objeto para a consciência, mas sim é aquilo que possibilita que algo seja tomado como um objeto (todo objeto é objeto para um eu). Ao procurar tornar o eu objeto de consideração para a consciência, ele teria de ser, ao mesmo tempo, o conhecedor e o conhecido, o sujeito e o objeto do mesmo ato de conhecimento, afinal, todo conhecer acontece a partir do próprio eu. Porém, não é possível que no conhecimento algo seja ao mesmo tempo objetivo e subjetivo, já que essas são esferas correlatas, mas opostas. Assim, ao tentar tornar o eu um objeto, ele acabaria por perder o próprio caráter de $e u$.

Desse modo, toda consideração em torno do eu envolve uma análise de sua relação com a consciência que pode ser descrita. Mas descrever a consciência é, na verdade, descrever seu conteúdo; nesse sentido, também, toda unificação e separação, toda unidade e multiplicidade devem ser analisadas no conteúdo da consciência e não como simples atos que são realizados nela. $\mathrm{O} e u$ só pode ser encontrado enquanto uma unidade da multiplicidade dos conteúdos da consciência; mas na medida em que os próprios conteúdos são experienciados a partir do $e u$, é questionável como o eu ele mesmo poderia ser um objeto para a consciência (já que os próprios objetos são objetos para o eu). Assim, o problema do eu remete, na verdade, para o problema da unidade da consciência, já que tudo que entra em questão aparece enquanto diferentes tipos de conteúdos presentes nela.

Diante dessas considerações, Heidegger reconhece que todas as quatro questões remetem, cada uma a seu modo, ao método de Natorp em relação à consciência. Uma ideia de fundo é a preconcepção básica do filósofo neo-kantiano: a constituição da consciência, isto é, a pressuposição de que deve haver uma determinação total da consciência e suas relações. A partir de tal pressuposição, o eu ele mesmo não poderia ser concebido por Natorp como um possível objeto 
de consideração para a consciência, pois o eu aparece como o fundamento para toda constituição, a unidade de todas as multiplicidades da consciência (aquilo mesmo que permite outras unidades). Se alguém vê uma cor, ou escuta um som, a cor e o som estão na consciência; ver e ouvir não são duas diferentes formas de consciência, mas sim duas coisas diferentes na consciência; a consciência por si já está constituída.

Assim, a "apreensão concreta primordial da vitalidade do conjunto de experiências vivas não é nada além do pensar da origem ligada à correlação dos conjuntos de constituição na correlação de algo objetivo e algo subjetivo" (HEIDEGGER, 2010, p. 105. GA 59, p. 138). Ou seja, procurar apreender a experiência viva é procurar entender a lógica de funcionamento presente na própria constituição da consciência e assim perceber, no que diz respeito a tal experiência, seu correlato objetivo e subjetivo. Nesse caso, porém, a experiência viva ela mesma não é apreendida, pois o que é tomado em consideração é apenas a lógica geral que a determinaria (ainda que a pretensão seja apreendê-la a partir dessa lógica geral, o fato é que nunca chegamos a ela concretamente, mas apenas ao funcionamento abstrato da lógica).

A consequência da pressuposição de Natorp é, segundo Heidegger, que ao segui-la "nada escapa à sistemática estrita que pode ser desenvolvida a partir dela" e qualquer tentativa de descrever algo concreto "é julgado de princípio como filosoficamente ingênuo, ou mesmo como não filosófico; ingênuo porque acrítico, acrítico porque não considera os pressupostos que servem de fundamento" (HEIDEGGER, 2010, p. 107. GA 59, p. 139). Assim, uma vez estabelecida como base a pressuposição da constituição da consciência, toda e qualquer questão que transcenda a esfera dessa consideração é tomada como equivocada, já que a própria filosofia acaba tendo por fundamento esse pressuposto teórico. A questão "toma o conjunto de relações [que formam a consciência] enquanto tal e, ao mesmo tempo, impede qualquer entrada de um momento do mundo-próprio pessoal" (HEIDEGGER, 2010, p. 108. GA 59, p. 140); isto é, qualquer consideração a partir das experiências do indivíduo concreto é vetada, uma vez que toda análise ocorre tendo como fundamento a universalidade da estrutura de constituição da consciência.

Também na busca pelo sentido da realização (Vollzug) da experiência viva teremos dificuldades: como entender o modo como as experiências vivas realizam-se na consciência? Uma vez que a realização ocorre sempre em um momento determinado e em uma consciência determinada, haveria algum tipo de universalidade nesse ponto? Segundo Heidegger, também aqui Natorp fornece uma explicação distante de qualquer mundo-próprio, pois para o filósofo neo-kantiano "a existência das experiências vivas [ocorre] em uma consciência 
Heidegger em confronto com a tradição: o problema da vida fáctica e a destruição fenomenológica contra Natorp e Dilthey
Dnda. Juliana Missaggia PUC-RS/CNPq

supratemporal" e embora possam ser diferentes em cada consciência quanto ao conteúdo, "a relação de ordenação é em princípio a mesma. (...) então o sentido da realização já está teoricamente objetivado" (HEIDEGGER, 2010, p. 114. GA 59, p. 152). Ou seja, ainda que haja diferenças de conteúdo (Gehalt) nas experiências vivas (já que as consciências podem pensar coisas diferentes), o modo como tais experiências serão vividas é determinado previamente por uma lógica de funcionamento da consciência, que ordenará e relacionará umas experiências com as outras de acordo com essa lógica prévia. Assim, a realização (Vollzug) da experiência terá um caráter universal, pois a lógica que a determina é universal e apreensível teoricamente.

Porém, Heidegger reconhece que um dos seus critérios para definir o caráter genuíno da realização é satisfeito por Natorp: como vimos, uma realização é genuína se acontece em relação com o mundo-próprio do Dasein concreto e se necessita de uma constante atualização. Ainda que o sentido de realização que possa ser encontrado na filosofia de Natorp seja completamente avesso à ideia de concretização no mundo-próprio - na medida em que ocorre a partir de um ponto de vista teórico e universal -, o critério de atualização é satisfeito, pois o filósofo neo-kantiano reafirma diversas vezes que o conhecimento não é algo estático e acabado em si, mas sim algo que exige uma constante renovação e atualização no infinito progresso da determinação da consciência. Ainda assim, Heidegger ressalta que o tipo de atualização defendida por Natorp não é aquela realizada na história, pois se trata de um processo dialético da autoconsciência absoluta.

Dito isso, não fica difícil entender como a concepção de Natorp, assim como seu pressuposto da constituição da consciência, distancia-se radicalmente do que estabelece Heidegger com sua pressuposição da busca das experiências a partir da vida concreta e do mundo-próprio do Dasein. O que Heidegger procurou mostrar com a análise das ideias de Natorp foi como seu pressuposto teórico - um caso paradigmático desse tipo de postura presente em muitos outros filósofos - determinou a resposta para todas as questões propostas, do mesmo modo que tornou inviável a apreensão das experiências vivas concretamente, já que o único modo como poderiam ser apreendidas é naquilo que elas têm de universal, o que é determinado pela própria constituição da consciência e suas relações entre os correlatos objetivos e subjetivos. Não há, em Natorp, sequer o espaço para algo de "irracional" nas experiências, pois toda experiência é algo dado na consciência e para o eu que forma a unidade da consciência, de modo que nada que possa ser chamado de experiência escapa dessa estrutura já previamente racional e logicamente determinada. 
Heidegger em confronto com a tradição: o problema da vida fáctica e a destruição fenomenológica contra Natorp e Dilthey
Dnda. Juliana Missaggia

PUC-RS/CNPq

\section{A análise da dificuldade a partir de Dilthey}

Heidegger inicia suas considerações sobre o pensamento de Dilthey lembrando que muitos não o consideram propriamente um filósofo, na medida em que - embora reconheçam a importância de Dilthey quanto ao seu tratamento da historicidade e das ciências humanas - alegam que não podemos encontrar em sua obra uma conclusão global e sistemática. Ainda que, segundo Heidegger, Dilthey tenha tido pretensões de sistematizar seu pensamento no fim da vida, de fato a maior parte de sua obra evita a fundação de um sistema; o que será avaliado, na análise heideggeriana, como algo positivo. $\mathrm{O}$ foco de tal análise será o desenvolvimento da teoria das ciências humanas em sua ligação com a historicidade e com a questão da vida concreta.

Para Dilthey, a filosofia relaciona-se necessariamente com a busca pelos fundamentos da objetividade e por encontrar uma clarificação para a vida ela mesma. O pensamento, em seu nível mais alto, encontra - e nesse ponto ele coincide com Natorp - com o conhecimento do conhecimento e a consciência da consciência; mas deve voltar-se, já em princípio, para a compreensão da vida, o que ocorre a partir das ciências humanas. Procurar apreender a vida humana e concreta envolve o reconhecimento de um fundamento comum que permite que as palavras e ações sejam compreendidas e comunicadas. Toda objetividade, criada e efetivada pelo fundamento comum que permite o entendimento compartilhado, é regulada por um conjunto teleológico de valores que é, por sua vez, englobado pelo contexto operativo (Wirkungszusammenhang) ${ }^{14}$. Por contexto operativo, Dilthey entende os fundamentos e bases de conhecimentos de uma época ou geração, o qual surge como o conceito basilar para as ciências humanas.

O elemento fundamental para o contexto operativo será o indivíduo, enquanto aquele que possibilita em primeiro lugar a unidade da vida. Procura-se uma teoria geral da unidade da vida que será possibilitada pela psicologia, a partir de sua análise da facticidade do indivíduo e do modo como ele vive tal unidade numa esfera pré-teórica, a qual deve ser apreendida través da descrição e análise imediata. Disso, segue-se então a ideia de uma psicologia analítica

14 Segundo o próprio Dilthey (1979, p. 197): "Um tal contexto operativo opera primariamente em indivíduos. Eles são os pontos de passagem dos sistemas de relações, os quais são uma fonte contínua de atividade. Consequentemente, em cada contexto, valores comuns e procedimentos ordenados para realizá-los são estabelecidos e aceitos como incondicionalmente válidos. Assim, em cada relação permanente entre valores individuais, regras e decisões, são desenvolvidos, tornados conscientes e consolidados pela reflexão. Essa atividade criativa, a partir das condições naturais que constantemente fornecem material e estímulo para isso, ocorrem em indivíduos, comunidades, sistemas culturais e nações, tornando-se consciente de si mesmo nos estudos humanos". (Modifico aqui a tradução de Wirkungszusammenhang). 
e descritiva ou ainda uma "psicologia estrutural", que terá como tarefas: "1. fornecer partes-transversais da vida mental; 2. apresentar partes longitudinais: biografia geral; 3 . determinar e assegurar o que resulta do contexto: o conjunto adquirido da vida mental" (HEIDEGGER, 2010, p. 121. GA 59, p. 157). O objetivo da psicologia estrutural é, portanto, apreender o chamado status conscientiae, isto é, as diversas relações entre a vida mental individual, o eu, e suas relações com o meio onde encontram-se. É importante perceber, porém, que essa análise não pretende descrever uma realidade fixa e acabada em si, pois o processo das experiências vivas apreendidas pela psicologia é dinâmico. Além disso, a relação entre o eu e o meio tem a pretensão de ser primordial, no sentido de ser concebida para além da análise meramente teórica ${ }^{15}$.

Na descrição da vida mental pela psicologia estrutural destacam-se três elementos presentes na consciência: representação (pensamento), sensibilidade e vontade. A representação é entendida por Dilthey como o conteúdo intencional, aquilo para o qual, por exemplo, a vontade pode ser dirigida. Por sensibilidade não deve-se entender apenas um conglomerado de sensações de prazer ou desprazer, ainda que a sensibilidade também envolva "aprovação e desaprovação, gosto e aversão e interesse em algo" (HEIDEGGER, 2010, p. 122. GA 59, p. 158). A partir disso, podem ser distinguidas duas linhas de desenvolvimento no mental: uma segundo o pensamento, outra segundo a vontade. A primeira vai das sensações pela via das associações até o processo do pensar (tratando do movimento do meio em direção ao eu). A segunda, conforme a vontade, diz respeito ao motivo pelo qual o eu decide sobre si mesmo numa ação (e descreve, portanto, o movimento do eu em direção ao meio).

Assim, surge a questão de como a vida mental está articulada nesse conjunto de estruturas. Haveria três pontos principais: 1. em cada um de seus momentos, a vida mental está presente como uma unidade; 2. ela mantém uma relação com o meio, adapta-se a ele (adaptação essa que não significa aqui algo biológico); 3 . a sequência de experiências vivas não pode ser determinada a partir de um princípio de causalidade, onde uma experiência é causa de outra e assim por diante.

Dilthey também reconhece que existem conceitos lógicos fundamentais que são válidos para a vida mental e que esta torna-se acessível a partir da chamada percepção interior. Por percepção interior não devemos entender um ato de reflexão isolado, tampouco algo com uma evidência absoluta - contrariando, nesse sentido, o que os fenomenólogos em geral pensam. Uma intelectualidade interior, assim como uma capacidade de conceitualidade, estão presentes em tal

15 Assim como no caso de Natorp, apresentamos aqui apenas muito resumidamente o pensamento de Dilthey. 
Heidegger em confronto com a tradição: o problema da vida fáctica e a destruição fenomenológica contra Natorp e Dilthey
Dnda. Juliana Missaggia PUC-RS/CNPq

percepção: "formas gerais de pensamento, realizações formais de separar, conectar, ligar, etc., têm a tarefa de elucidar o complexo mental", mas de tal modo que o que é elucidado permanece no complexo mental, pois "(...) toda significação mental só pode ser interpretada a partir do complexo, nunca de modo isolado" (HEIDEGGER, 2010, p. 124. GA 59, p. 163).

Diante dessa breve exposição do pensamento de Dilthey, Heidegger passa a buscar a pressuposição ali presente, a partir do procedimento da destruição fenomenológica. Em primeiro lugar, procura descrever três momentos do caráter relacional da percepção interna. O primeiro diz respeito à sua intelectualidade interna: para Dilthey o processo lógico presente na vida mental faz parte da percepção interna, não sendo algo que a contradiz, pois a própria experiência viva possui certa racionalidade, isto é, ela já é compreensível em si mesma. Ainda que essa posição de Dilthey seja bastante próxima à concepção heideggeriana, aqui Heidegger acredita que o problema esteja colocado, porém não resolvido nem levado até suas últimas consequências. $\mathrm{O}$ segundo momento trata do fato de que o eu experiência a si mesmo a partir de um todo da situação dada, o que remete ao conceito de contexto operativo; Heidegger concorda com esse fator contextual e situacional da experiência do eu, porém acredita que Dilthey o elabora num viés equivocado, a partir de uma ideia de compreensão. O terceiro momento da percepção interna em seu caráter de relação chama a atenção para o fato de que o que é acessível para um determinado sujeito possui em si uma certa importância, um certo valor ou desvalor para esse sujeito, o que deve servir de guia para a análise.

Segundo Heidegger, Dilthey é, em certo sentido, uma oposição radical para Natorp; isso se evidencia, por exemplo, no seguinte fato: enquanto para o primeiro o eu é um centro fundamental de unidade para o conjunto ou complexo da vida mental, para Natorp o eu funciona como algo que tem um papel secundário, pois é dado a partir da consideração da consciência e acaba sendo, em última instância, um eu puro e universal, distante de todo $e u$ concreto. Além disso, segundo Heidegger, em Dilthey o complexo de experiências vivas é visto de tal modo que "suas estruturas tornam-se claras como a condição de possibilidade de compreensão da unidade da vida", de fato, o complexo de experiências contém aquilo que torna possível tal unidade, pois "todo complexo possui um valor funcional como a condição de possibilidade para interpretar ou compreender a vida" (HEIDEGGER, 2010, p. 127. GA 59, p. 165). Isso possibilita também uma resposta - embora uma resposta bastante geral - para as questões que guiavam a análise, sobre como o caráter de unidade e multiplicidade das experiências vivas são significadas na posse da experiência concreta, bem como o problema da apreensão do $e u$ e sua relação com tais experiências. 
Para Dilthey, o fenômeno da vida: 1. é um complexo efetivo de relações dialéticas e 2. possui um conjunto de experiências vivas que ocorre em um complexo histórico. A vida ocorre necessariamente como algo em desenvolvimento, o qual pode ser articulado e racionalizado (sem por isso perder seu caráter essencialmente histórico). Ainda que a posição de Dilthey pareça de fato bastante próxima da concepção heideggeriana, Heidegger alega que Dilthey concebe o complexo efetivo das experiências como algo circunstancial e que mantém um ideal de humanidade que guia sua investigação, chegando por isso à sua análise do pensamento, da sensibilidade e da vontade como os três elementos principais da vida mental. Segundo Heidegger "Dilthey é ele mesmo pouco claro sobre aquilo contra o qual rivaliza. Ele não percebe que somente um radicalismo que torne todos os conceitos questionáveis pode nos levar adiante. Todo material conceitual deve ser novamente determinado na apreensão primordial" (HEIDEGGER, 2010, p. 129. GA 59, p. 168).

\section{Conclusões}

Diante de tais análises, Heidegger reconhece que seu procedimento resumiu-se sobretudo a negações - a partir da destruição fenomenológica de duas posições importantes da filosofia contemporânea -, mas que não houve uma construção positiva das questões, de modo a desenvolver novas considerações sobre o tema. Porém, alguns importantes resultados (os quais guiarão a análise construtiva) foram alcançados: em primeiro lugar, ficou evidente a precariedade do ponto de partida essencialmente teórico para lidar com os problemas filosóficos; procurar formular conceitos filosóficos com a mesma metodologia ou postura com que se formula conceitos científicos, é cair no erro grave de impedir o próprio caminho até um desenvolvimento genuinamente filosófico das questões. Além disso, fica claro que essas concepções teóricas e aparentemente "radicais" escondem uma série de pressupostos que devem ser explicitados para o avanço da discussão - e foi justamente isso o que a destruição possibilitou.

Outro ganho importante - talvez o mais importante deles - foi o reconhecimento de que devemos partir de algum lugar e que, portanto, devemos ter uma pressuposição que guia a análise. Se o ponto de partida teórico da filosofia tradicional não encontrou um caminho adequado, isso aponta, segundo Heidegger, para o erro de não perceber que na base mesma de qualquer possibilidade de filosofar está o Dasein concreto na sua vida fáctica. Somente a 
partir desse ente é possível qualquer filosofar e, portanto, é a partir dele - do modo mais concreto possível - que devemos partir. Será essa a decisão que guiará o desenvolvimento "construtivo" dos problemas.

O procedimento da destruição fenomenológica é, a despeito de seu caráter desconstrutor, justamente esse: reavaliar a tradição para poder aprender também com os seus erros. Reconhecer os pressupostos que guiavam as análises e encontrar aqueles que parecem mais adequados. De fato, com a destruição fenomenológica, os pressupostos implícitos na filosofia se tornam evidentes, pois a tradição tem uma influência clara sobre todos os conhecedores da história da filosofia, não somente na terminologia que será empregada mas também nas questões e nos prejuízos inconscientes. Heidegger reconhece que sua própria investigação não está livre de tal influência e acredita que a melhor maneira de proceder diante disso é procurar reconhecer e assumir o peso da tradição, ao mesmo tempo que efetuese uma destruição crítica de tal legado: "necessariamente pertence a interpretação conceitual do ser e de suas estruturas (...) uma destruição - um processo crítico no qual os conceitos tradicionais que devem ser necessariamente empregados, são desconstruídos até as pesquisas que os originaram" (HEIDEGGER, 1988, p. 22-3, GA 24, p. 30-31). A maneira de proceder será tratar o pensamento filosófico da tradição de modo que seja reavaliado e reassumido criticamente pelo filósofo, mesmo que para tanto seja necessário modificar os conceitos tradicionais. Isso significa não uma negação, mas sim uma apropriação positiva da tradição.

BERGSON, Henri. Essai sur les données immédiates de la conscience. Paris: Presses universitaires de France, 1945.

DILTHEY, Wilhelm. Selected Writings. Trans. By Hans. P. Rickman (org). New York: Cambridge University Press, 1979.

HEIDEGGER, Martin. (GA 20). Prolegomena zur Geschichte des Zeitbegriffs (Sommersemester 1925). Frankfurt am Main: Vittorio Klostermann, 1979.

\section{Referência Bibliográfica}

- (GA 24). Die Grundprobleme der Phänomenologie (Sommersemester 1927). Frankfurt am Main: Vittorio Klostermann, 1975.

(GA 24; SS 1927). The Basic Problems of Phenomenology. Translated by Albert Hofstadter. Bloomington, Indianapolis: Indiana University Press, 1988.

(GA 59; SS 1920). Die Phänomenologie der Anschauung und des Ausdrucks: Theorie der philosophischen Begriffsbildung. Frankfurt: ed. C.Strube, 1993. 
- (GA 59; SS 1920). Phenomenology

of Intuition and Expression. Translated by Tracy

Colony. London: Continuum Books, 2010.

HUSSERL, Edmund. Meditaciones cartesianas.

Tradução de M. García-Baró e J. Gaos. México:

Fondo de Cultura Económica, 1986.

JOLIVET, Servanne. La notion de "destruction" chez le jeune Heidegger. Horizons philosophiques, vol. 14, no 2, 2004, p. 81-104.

KISIEL, Theodore. \& VAN BUREN, J. (orgs). Reading Heidegger from the Start. Albany: State University Press of New York, 1995.

NATORP, Paul. Psychologie générale selon la méthode critique. Paris : J. Vrin, 2007.

RICKERT, Heinrich. The Limits of Concept Formation in Natural Science: A Logical. Introduction to the Historical Sciences. Trans. By Guy Oakes. New York: Cambridge University Press, 1986. 